\title{
The epidemiology of boys' youth lacrosse injuries in the 2015 season
}

\author{
Zachary Y. Kerr ${ }^{1 *}$, Shane V. Caswell ${ }^{2}$, Andrew E. Lincoln ${ }^{3}$, Aristarque Djoko ${ }^{1}$ and Thomas P. Dompier ${ }^{1}$
}

\begin{abstract}
Background: Participation in boys' youth lacrosse has dramatically increased in recent years. Yet, research on the incidence of youth lacrosse injuries is limited. This study describes the epidemiology of boys' youth lacrosse injuries.

Findings: Aggregate injury and exposure data was collected from 550 boys' youth lacrosse players (aged 9-15 years) from eight leagues in four states. Injury frequencies and rates with $95 \%$ confidence intervals (Cl) were calculated. Rate ratios (RR) accounting for clustering within league compared game and practice injury rates. During the 2015 season, 155 injuries were reported for a rate of 12.98/1000AE (95\% Cl:10.93-15.02). Most injuries occurred during games $(60.0 \%)$, resulted in time loss $<24 \mathrm{~h}(83.9 \%)$, and were in the U13/U15 divisions (69.0\%). Most injuries were to the lower extremity (45.2\%), and diagnosed as contusions (51.6\%). Ten concussions (6.5\%) were reported, with seven occurring in the U13/U15 divisions. All injuries resulting in time loss $\geq 24 \mathrm{~h}$ in the U9/U11 divisions were concussions. Most injuries were due to equipment contact, particularly stick contact (35.5\%) and ball contact (14.2\%). Injury rates were higher in games than practices overall (RR $=2.90 ; 95 \% \mathrm{Cl}: 1.81-4.89$ ), and for concussions only $(\mathrm{RR}=4.51 ; 95 \% \mathrm{Cl}: 1.89-11.03)$. Between the U9/U11 and U13/U15 divisions, the overall-injury rate was higher in U9/U11 ( $\mathrm{RR}=1.23 ; 95 \% \mathrm{Cl}: 1.05-1.44)$.

Conclusions: Our boys' youth lacrosse injury rate was higher than those previously reported, but may be more precise given the larger sample. The large proportion of equipment contact injuries demonstrate the need to adopt currently available coaching instruction and age-appropriate US Lacrosse rules that could better protect youth players.
\end{abstract}

Keywords: Epidemiology, Youth sports

\section{Findings} Introduction

Participation in youth lacrosse ( $\leq 15$ years) has increased in recent years, with 2014 estimates of 279,771 youth participants in the United States (US Lacrosse "Participation..." 2015) Although lacrosse injury data are available at the high school and college levels (Dick et al. 2007; Xiang et al. 2014), youth level data are limited. The recent study involving male players aged 9-15 years estimated an injury rate of 8.7/1000 athlete-exposures (AE) from 22 injuries (Lincoln et al. 2014) Data utilizing larger samples of youth lacrosse players will aid the development of sports injury prevention strategies to reduce injury incidence and severity. This study describes the epidemiology of injuries in boys' youth lacrosse in the 2015 season.

\footnotetext{
* Correspondence: zkerr@datalyscenter.org

${ }^{1}$ Datalys Center for Sports Injury Research and Prevention, 401 W. Michigan

St., Suite 500, Indianapolis, IN 46202, USA

Full list of author information is available at the end of the article
}

\section{Methods}

This study employed a one-season observational cohort design. A total of 550 boys' youth lacrosse players from eight leagues in four states (Indiana, Massachusetts, South Carolina, and Virginia) and between the ages of 9-15 (mean age: 12 \pm 2 ) were followed over the 2015 season. The study protocol was approved by the Western Institutional Review Board (Puyallup, WA).

Data collection for youth lacrosse parallels that of previous youth football studies that have been explained in detail previously (Kerr et al. 2015). On-site athletic trainers (ATs) reported injury and exposure data from all games and practices into a single injury documentation application called the Injury Surveillance Tool (IST [Datalys Center, Indianapolis, IN]). All ATs received standardized training in the use of the IST. De-identified injury and exposure information were exported to a central database and reviewed by quality control staff on a weekly basis.

\section{定 Springer}

C 2016 Kerr et al. Open Access This article is distributed under the terms of the Creative Commons Attribution 4.0 International License (http://creativecommons.org/licenses/by/4.0/), which permits unrestricted use, distribution, and reproduction in any medium, provided you give appropriate credit to the original author(s) and the source, provide a link to the Creative Commons license, and indicate if changes were made. 
An injury was defined as an injury/illness occurring during a league-sanctioned game or practice that required AT evaluation (Kerr et al. 2015). A time loss (TL) injury restricted participation for $\geq 24 \mathrm{~h}$; a non-time loss (NTL) injury restricted participation for $<24 \mathrm{~h}$. An athleteexposure (AE) was defined as one player participating in one game or one practice. Data were analyzed using SASEnterprise Guide software (version 5.1; SAS Institute Inc., Cary, NC). Frequencies, injury rates, and rate ratios (RR) were calculated by event type (competition vs. practice) and division (U9/U11 vs. U13/U15). To account for clustering within league, generalized estimating equations with an exchangeable covariance structure were used for all analyses. Clusters (league) were based upon the level at which each athletic trainer covered youth lacrosse. RRs with $95 \%$ confidence intervals (CIs) not including 1.00 were considered statistically significant.

\section{Results}

\section{Overall frequencies and rates}

During the 2015 season, 155 injuries were reported across $11,946 \mathrm{AE}$, for an overall injury rate of 12.98/1000AE (95\% CI:10.93-15.02; Table 1). Most injuries occurred during games (60.0 \%), were NTL (83.9 \%). The TL-injury rate was 2.09/1000AE (95 \% CI:1.27-2.891).

Most injuries were to the lower extremity (45.2\%), and were diagnosed as contusions (51.6 \%) and sprains (14.8\%; Table 2). Most injuries were due to equipment contact, particularly stick contact (35.5\%) and ball contact (14.2\%), followed by player contact (18.1\%; Table 3). In addition, common injury activities included general play (20.0 \%), running (15.5\%), defending (12.9\%), and chasing a loose ball (12.3\%). Only three injuries $(1.9 \%)$ were reported due to checking.

Ten concussions $(6.5 \%)$ were reported. The ten concussions were due to player contact $(n=6)$, stick contact $(n=3)$, and ball contact $(n=1)$. The common injury activity was chasing a loose ball $(n=3)$. No anterior cruciate ligament $(\mathrm{ACL})$ injuries were reported.

The overall-injury rate was higher in games than in practices ( $R R=2.90 ; 95 \%$ CI:1.81-4.89; Fig. 1). This difference was attenuated when restricted to TL injuries only $(\mathrm{RR}=1.78 ; 95 \% \mathrm{CI}: 1.21-2.64)$, but higher when restricted to concussions only ( $\mathrm{RR}=4.51$; $95 \% \mathrm{CI}: 1.89-11.03$ ).

\section{Comparisons by division}

The U13/U15 divisions accounted for the largest proportion of overall injuries (69.0\%), TL injuries $(92.0 \%)$, and concussions (70.0 \%; Table 1). All the TL injuries reported in the U9/U11 divisions were concussions. The overallinjury rate was higher in U9/U11 than U13/U15 division $(\mathrm{RR}=1.23$; 95 \% CI:1.05-1.44; Fig. 1), but lower when restricted to TL injuries only ( $R R=0.44 ; 95 \% \mathrm{CI}: 0.24-0.83$ ). Concussion rates did not differ between the U9/U11 and U13/15 divisions ( $\mathrm{RR}=1.26$; $95 \% \mathrm{CI}: 0.45-3.49$ ).

Few differences were found when comparing the distribution of injuries in the U9/U11 and U13/U15 divisions (Table 2). Compared to the U9/U11 divisions, the U13/U15 divisions had larger proportions of injuries diagnosed as sprains $(19.6 \%$ vs. $4.2 \%)$ and due to non-contact (16.8 \% vs. $2.1 \%)$. The U13/U15 divisions also had larger proportions of injuries due to ball contact (16.8\% vs. $2.1 \%)$ and stick contact (16.8 \% vs. $8.3 \%)$.

Table 1 Injury counts and rates in boys' youth lacrosse, overall and by division, 2015 season

\begin{tabular}{|c|c|c|c|c|c|c|c|}
\hline \multirow{2}{*}{$\begin{array}{l}\text { Division and } \\
\text { event type }\end{array}$} & \multirow[t]{2}{*}{$\mathrm{AEs}^{\mathrm{a}}$} & \multicolumn{3}{|c|}{ Injury counts } & \multicolumn{3}{|c|}{ Injury rates per 1000AE (95 \% Cl) } \\
\hline & & All injuries & Time loss injuries only ${ }^{b}$ & Concussions & All injuries & Time loss injuries only & Concussion \\
\hline \multicolumn{8}{|l|}{ Overall } \\
\hline Game & 4075 & 93 & 12 & 7 & $22.82(18.18-27.46)$ & $2.94(1.28-4.61)$ & $1.72(0.45-2.99)$ \\
\hline Practice & 7871 & 62 & 12 & 3 & $7.88(5.92-9.84)$ & $1.65(0.75-2.55)$ & $0.38(0.00-0.81)$ \\
\hline Overall & 11946 & 155 & 23 & 10 & $12.98(10.93-15.02)$ & $2.09(1.27-2.91)$ & $0.84(0.32-1.36)$ \\
\hline \multicolumn{8}{|l|}{ U9/U11 } \\
\hline Game & 1151 & 31 & 1 & 1 & $26.93(17.45,36.41)$ & $0.87(0.00,2.57)$ & $0.87(0.00,2.57)$ \\
\hline Practice & 2029 & 17 & 2 & 2 & $8.38(4.40,12.36)$ & $0.99(0.00,2.35)$ & $0.99(0.00,2.35)$ \\
\hline Overall & 3180 & 48 & 3 & 3 & $15.09(10.82,19.36)$ & $0.94(0.00,2.01)$ & $0.94(0.00,2.01)$ \\
\hline \multicolumn{8}{|l|}{ U13/U15 } \\
\hline Game & 2924 & 62 & 11 & 6 & $21.20(15.93,26.48)$ & $3.76(1.54,5.99)$ & $2.05(0.41,3.69)$ \\
\hline Practice & 5842 & 45 & 11 & 1 & $7.70(5.45,9.95)$ & $1.88(0.77,3.00)$ & $0.17(0.00,0.51)$ \\
\hline Overall & 8766 & 107 & 22 & 7 & $12.21(9.89,14.52)$ & $2.51(1.46,3.56)$ & $0.80(0.21,1.39)$ \\
\hline
\end{tabular}


Table 2 Injury counts, by body part and diagnosis, in youth boys' lacrosse, overall and by division, 2015 season

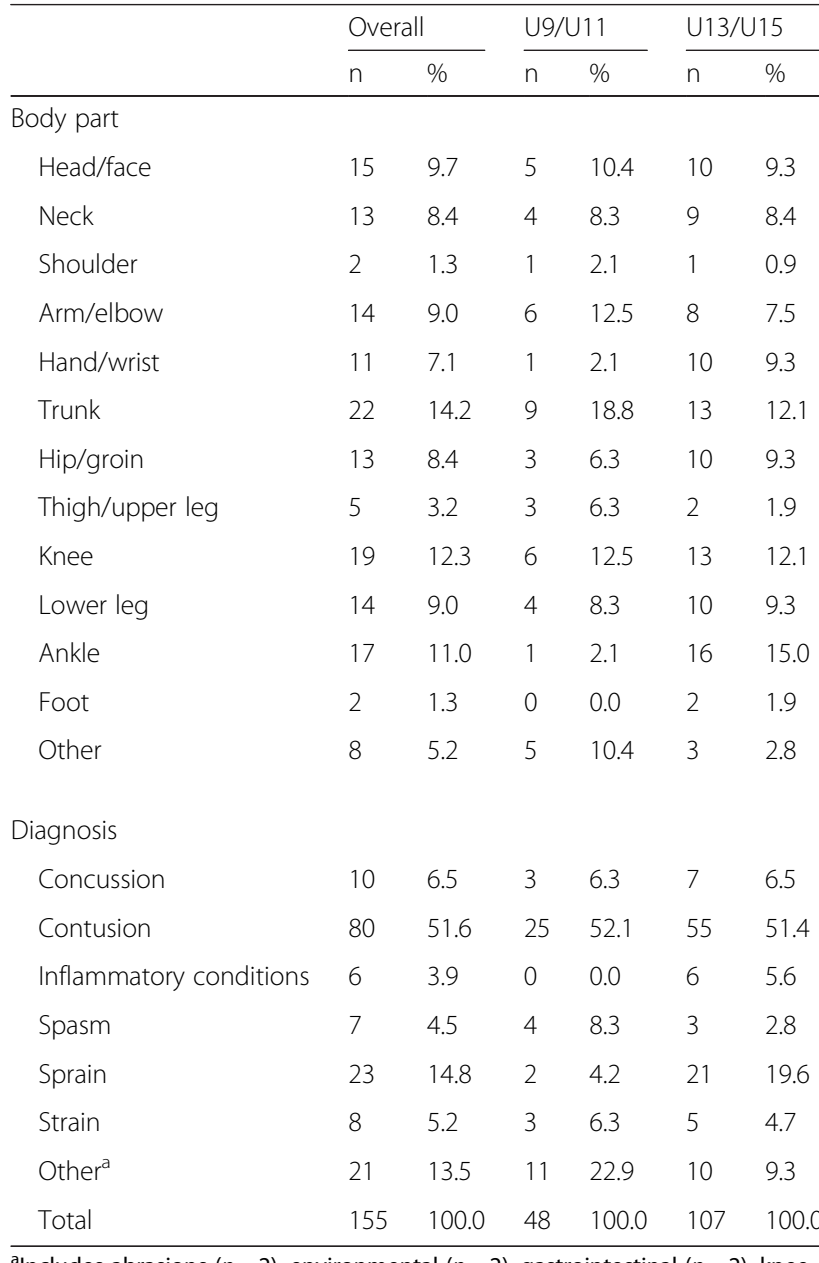

ancludes abrasions $(n=2)$, environmental $(n=2)$, gastrointestinal $(n=2)$, knee pain $(n=2)$, respiratory $(n=2)$, and other injuries that were reported only once

\section{Discussion}

Youth lacrosse is one of the fastest growing sports in the US (US Lacrosse "Participation..." 2015) Research in youth lacrosse is limited, yet necessary, to drive the development of interventions to reduce injury incidence and severity. Our study utilizes a large sample of boys' youth lacrosse players across eight leagues in four states, and estimated an injury rate higher than that previously reported (12.98 vs. 8.7/1000AE) (Lincoln et al. 2014). However, our study included an additional younger division (U9). Lincoln et al. (2014) noted that the highest injury rate was found in the younger division (U11). In our study, the overall-injury rate in the U9/U11 divisions was higher than that of the U13/U15 divisions (15.09 vs. $12.21 / 1000 \mathrm{AE})$. In contrast, the TL-injury rate in the U13/U15 divisions was higher than that of the U9/U11 divisions (2.51 vs. $0.94 / 1000 \mathrm{AE})$. This is expected since upper youth divisions, according to US Lacrosse rules, allow for more bodily contact (US Lacrosse "2015 rules..." 2015).
Table 3 Injury counts, by injury mechanism and injury activity, in youth boys' lacrosse, overall and by division, 2015 season

\begin{tabular}{|c|c|c|c|c|c|c|}
\hline & \multicolumn{2}{|c|}{ Overall } & \multicolumn{2}{|c|}{ U9/U11 } & \multicolumn{2}{|c|}{ U13/U15 } \\
\hline & $n$ & $\%$ & $n$ & $\%$ & $n$ & $\%$ \\
\hline \multicolumn{7}{|l|}{ Injury mechanism } \\
\hline Player contact & 28 & 18.1 & 9 & 18.8 & 19 & 17.8 \\
\hline Surface contact & 12 & 7.7 & 5 & 10.4 & 7 & 6.5 \\
\hline Stick contact & 55 & 35.5 & 20 & 41.7 & 35 & 32.7 \\
\hline Ball contact & 22 & 14.2 & 4 & 8.3 & 18 & 16.8 \\
\hline Non-contact & 19 & 12.3 & 1 & 2.1 & 18 & 16.8 \\
\hline Overuse & 9 & 5.8 & 2 & 4.2 & 7 & 6.5 \\
\hline Illness/infection & 5 & 3.2 & 5 & 10.4 & 0 & 0.0 \\
\hline Other/Unknown & 5 & 3.2 & 2 & 4.2 & 3 & 2.8 \\
\hline \multicolumn{7}{|l|}{ Injury activity } \\
\hline Blocking shot & 5 & 3.2 & 1 & 2.1 & 4 & 3.7 \\
\hline Chasing loose ball & 19 & 12.3 & 8 & 16.7 & 11 & 10.3 \\
\hline Checking & 3 & 1.9 & 2 & 4.2 & 1 & 0.9 \\
\hline Conditioning & 2 & 1.3 & 0 & 0.0 & 2 & 1.9 \\
\hline Defending & 20 & 12.9 & 4 & 8.3 & 16 & 15.0 \\
\hline Face off & 2 & 1.3 & 1 & 2.1 & 1 & 0.9 \\
\hline General play & 31 & 20.0 & 10 & 20.8 & 21 & 19.6 \\
\hline Goaltending & 6 & 3.9 & 2 & 4.2 & 4 & 3.7 \\
\hline Handling ball & 2 & 1.3 & 0 & 0.0 & 2 & 1.9 \\
\hline Passing & 8 & 5.2 & 3 & 6.3 & 5 & 4.7 \\
\hline Receiving Pass & 4 & 2.6 & 1 & 2.1 & 3 & 2.8 \\
\hline Running & 24 & 15.5 & 8 & 16.7 & 16 & 15.0 \\
\hline Shooting & 17 & 11.0 & 4 & 8.3 & 13 & 12.1 \\
\hline Other & 12 & 7.7 & 4 & 8.3 & 8 & 7.5 \\
\hline Total & 155 & 100.0 & 48 & 100.0 & 107 & 100.0 \\
\hline
\end{tabular}

TL-injury rates $($ game $=2.94 / 1000 \mathrm{AE}$; practice $=1.65 /$ $1000 \mathrm{AE})$ utilized an injury definition consistent with previous research (Dick et al. 2007; Xiang et al. 2014), and were found to be lower than those in college (game = 12.58/1000AE; practice $=3.24 / 1000 \mathrm{AE})($ Dick et al. 2007). Youth injury rates were similar to high school rates (game $=3.61 / 1000 \mathrm{AE} ; \quad$ practice $=1.51 / 1000 \mathrm{AE}) \quad($ Xiang et al. 2014), particularly within the U13/U15 divisions. The similar findings may be due to US Lacrosse rules allowing more bodily contact in upper divisions (US Lacrosse "2015 rules..." 2015). However, unlike high school and college, where most injuries were due to player contact and non-contact (Dick et al. 2007; Xiang et al. 2014), the largest proportion of youth lacrosse injuries were due to equipment contact, with over a third from stick contact. Potential injury mechanism differences may highlight the overall lower skill level of youth lacrosse compared with high school and college levels. Given our data originating from only one season, 


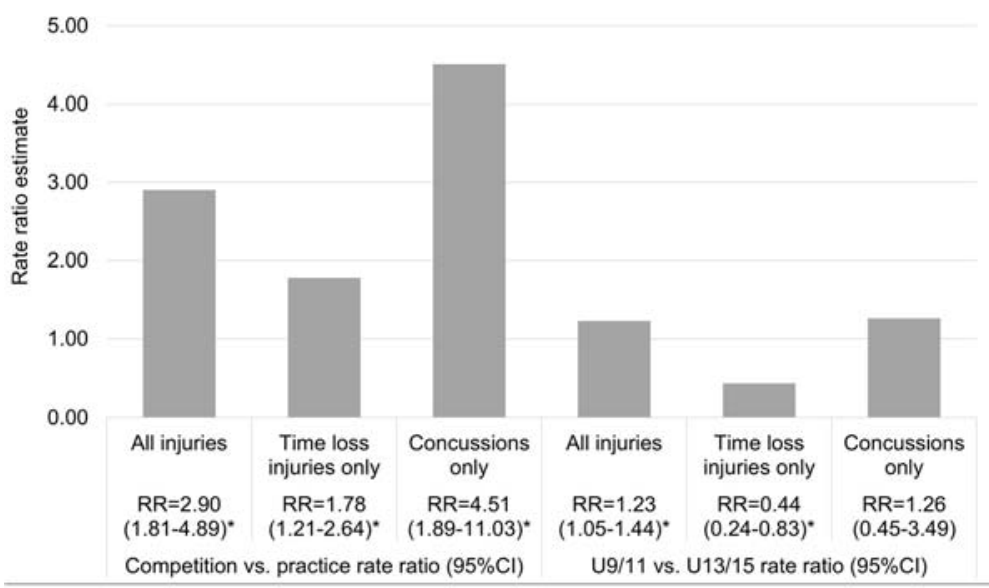

NOTE: Rate ratios and $95 \% \mathrm{Cls}$ account for clustering within league; practice and U13/15 served as the referents for the event type and division comparisons, respectively; "denotes $95 \% \mathrm{Cl}$ not including 1.00 ); time loss injuries are those resulting in participation restriction of at least 24 hours

Fig. 1 Rate ratios in boys' youth lacrosse, by event type and division, 2015 season

continued surveillance is required to obtain more precise estimates of potential variations by division within youth lacrosse and across competition levels.

The proportion of boys' youth lacrosse injuries due to checking were low. The 2015 US Lacrosse Boys Youth Rules prohibit body checking in the U9/U11 divisions, and allow for limited body checking in the U13/U15 divisions (US Lacrosse "2015 rules..." 2015). Further efforts to ensure proper development of stick and body checking skills through coaching education and rules enforcement are warranted in throughout all divisions.

As in previous youth lacrosse research (Lincoln et al. 2014), most injuries were minor and diagnosed as contusions. Findings may vary from those at the high school and college levels (Dick et al. 2007; Xiang et al. 2014), where most injuries were sprains and concussions, due to our injury definition including NTL injuries (Kerr et al. 2015). Nevertheless, ten concussions were reported, with most occurring in competitions and from player contact. This is similar to recent research that analyzed video footage in high school boys' lacrosse, finding that all 34 concussions captured were due to player contact (Lincoln et al. 2013). More definitive information on player and opponent activity would be useful to determine whether concussed players (or those that experience another injury) were defenseless. Previous research identified nearly half of all concussions in high school lacrosse to be associated with defenseless hits (Lincoln et al., 2013). If the trend holds at the youth level, efforts to enforce existing rules to limit defenseless hits may be warranted.

Although our sample originates from eight leagues in four states, findings were based on a small proportion of boys' youth lacrosse players estimated in the United States and one season (US Lacrosse "Participation..." 2015). Our findings may not be generalizable to other youth lacrosse players. Under-diagnosis and/or underreporting of injuries may have occurred if youth players opted not to seek on-site care, or experienced delayed onset of symptoms after leaving the youth lacrosse setting. However, ATs are experienced professionals trained to accurately detect injury. Lastly, team- and league-based variations, such as coaching experience and certification (US Lacrosse "Certification..." 2015), the rate of participation growth (US Lacrosse "Participation..." 2015), skill level, and the numbers of games and practices across a season were not accounted for in the study, yet should be in future research.

Our boys' youth lacrosse injury rate was higher than those previously reported. However, this estimate may be more precise given the larger sample. Continued surveillance across multiple seasons while accounting for coach-, team-, league-, and location-based variations will provide additional information regarding the epidemiology of youth lacrosse injuries. In addition, interventions may be warranted to reduce injury incidence. This can include adoption of age-appropriate rules to reduce exposure to player contact, enforcement of rules limiting defenseless hits, and ensuring proper development of checking skills through coaching education.

Abbreviations
AT: Athletic trainer; NTL: Non-time loss; TL: Time loss.

Competing interests

The author(s) declare that they have no competing interests.

\section{Authors' contributions}

ZK designed the study, secured the funding, led acquisition of the data, supervised the statistical analysis, interpreted the results, and oversaw the development of the manuscript. SC designed the study, secured the funding, assisted in the supervision of statistical analyses, interpreted the results, and contributed to drafting and revising the manuscript. AL assisted in the supervision of statistical analyses, interpreted the results, and contributed to 
drafting and revising the manuscript. AD performed the computer programming, data management, and statistical analysis, and contributed to drafting and revising the manuscript. TD contributed to obtaining funding, the acquisition of the data, interpreting the results, and critical revision of the manuscript. All authors read and approved the final manuscript.

\section{Acknowledgements}

This study would not be possible without the assistance of the athletic trainers and youth leagues who participated in the program.

\section{Funding}

This project was funded by National Operating Committee on Standards for Athletic Equipment (NOCSAE). The content of this report is solely the responsibility of the authors and does not necessarily reflect the views of NOCSAE.

\section{Author details}

'Datalys Center for Sports Injury Research and Prevention, 401 W. Michigan St., Suite 500, Indianapolis, IN 46202, USA. ${ }^{2}$ George Mason University, Sports Medicine Assessment, Research \& Testing (SMART) Laboratory, 10900 University Blvd. MS 4E5, Manassas, VA 20110, USA. ${ }^{3}$ MedStar Sports Medicine Research Center, 201 E. University Parkway, 764 Bauernschmidt Bldg, Baltimore, MD 21218, USA.

\section{Received: 19 November 2015 Accepted: 14 January 2016}

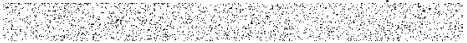

\section{References}

Dick R, Lincoln AE, Agel J, Carter EA, Marshall SW, Hinton RY. Descriptive epidemiology of collegiate women's lacrosse injuries: National Collegiate Athletic Association Injury Surveillance System, 1988-1989 through 2003-2004. J Athl Train. 2007:42:262-9.

Kerr ZY, Marshall SW, Simon JE, Hayden R, Snook EM, Dodge T, et al. Injury rates in age-only versus age-and-weight playing standard conditions in American youth football. Ortho J Sports Med. 2015. doi:10.1177/2325967115603979.

Lincoln AE, Caswell SV, Almquist JL, Dunn RE, Hinton RY. Video incidence analysis of concussions in boys' high school lacrosse. Am J Sports Med. 2013;41(4):756-61.

Lincoln AE, Yeger-McKeever M, Romani W, Hepburn LR, Dunn RE, Hinton RY. Rate of injury among youth lacrosse players. Clin J Sports Med. 2014;24(4):355-7.

US Lacrosse. 2015 rules for boys youth lacrosse. In: US Lacrosse. 2015. http://uww. uslacrosse.org/portals/1/documents/pdf/rules/2015-boys-youth-rules.pdf. Accessed November 16, 2015.

US Lacrosse. Certification information. In: US Lacrosse. 2015. http://www. uslacrosse.org/participants/coaches/coaching-education-program/ certification-information.aspx. Accessed November 16, 2015.

US Lacrosse. Participation Survey 2014. In: US Lacrosse. 2015. http://www. uslacrosse.org/Portals/1/documents/pdf/about-the-sport/2014-participationsurvey.pdf. Accessed November 16, 2015.

Xiang J, Collins CL, Liu D, McKenzie LB, Comstock RD. Lacrosse injuries among high school boys and girls in the United States academic years 2008-2009 through 2011-2012. Am J Sports Med. 2014;42(9):2082-8.

\section{Submit your manuscript to a SpringerOpen ${ }^{\circ}$ journal and benefit from:}

- Convenient online submission

- Rigorous peer review

- Immediate publication on acceptance

- Open access: articles freely available online

- High visibility within the field

- Retaining the copyright to your article 